\title{
To compare the efficacy of two doses of intraperitoneal bupivacaine for pain relief after operative laparoscopy in gynecology
}

Neena Malhotra $\cdot$ Charu Chanana $\cdot$ Kallol K. Roy $\cdot$

Sunesh Kumar · Vimi Rewari · J. B. Sharma

Published online: 11 January 2009

(C) Springer-Verlag 2009

Erratum to: Arch Gynecol Obstet (2007) 276:323-326

DOI 10.1007/s00404-007-0337-1

Unfortunately, one author was misspelled. The correct author list is given here.

Neena Malhotra $\cdot$ Charu Chanana $\cdot$ Kallol K. Roy $\cdot$ Sunesh Kumar · Vimi Rewari · J. B. Sharma

The online version of the original article can be found under doi:10.1007/s00404-007-0337-1.

N. Malhotra · C. Chanana · K. K. Roy · S. Kumar · J. B. Sharma

Department of Obstetrics and Gynecology,

All India Institute of Medical Sciences,

New Delhi, India

V. Rewari

Department of Anaesthesiology,

All India Institute of Medical Sciences,

New Delhi, India

C. Chanana $(\bowtie)$

\#281, University Place, 951, 18th Street South,

Birmingham, AL 35205, USA

e-mail: charuchanana@ rediffmail.com 